\title{
EMPODERAMENTO FEMININO COMO INSTRUMENTO DE COMBATE À VIOLÊNCIA POLÍTICA ${ }^{1}$
}

\author{
Women's empowerment as na instrument in fighting political violence
}

\section{Elizete Lanzoni Alves}

\begin{abstract}
Resumo: O objeto do artigo é a análise do empoderamento feminino, enquanto fortalecimento da mulher no alcance de sua autonomia emocional, financeira e política, como hábil instrumento no combate às violências, sobretudo, a institucional que atinge as mulheres nos próprios partidos políticos. A partir de uma breve incursão histórica sobre a mulher na sociedade e suas primeiras conquistas políticas, é possível verificar que a atualidade não reflete o ideal, mas, não deixa de representar um avanço, mesmo que a passos lentos. As conquistas jurídicas da mulher no campo político é um caminho sem volta e a continuidade da luta perfaz uma realidade em prol da igualdade de condições e oportunidades entre homens e mulheres na sociedade e na política. O método utilizado na fase da coleta e na estruturação da narrativa foi o indutivo, e a técnica de pesquisa bibliográfica em obras, artigos, legislação e sites institucionais, como o IBGE e TSE, deram o suporte necessário para a elaboração do trabalho. Ao final, é possível verificar que a violência institucional partidária, por vezes silenciosa, outras não, atinge as mulheres, representando forte barreira à participação da mulher na política.
\end{abstract}

Palavras-chave: Empoderamento feminino. Participação política da mulher. Combate à violência política.

\begin{abstract}
The object of this article is the analysis of female empowerment, whilst the strengthening of women in the attainment of their emotional, financial, and political autonomy, as skillful instrument in fighting violence, specially institutional violence, that affects women in their own political parties. From a brief historical stu$\mathrm{dy}$ about women in society and their political achievements, it is possible to confirm that recent standards do not reflect the ideal, but still represent progress, even though, slow. Women's legal achievements in the political field are a path of no return and the continuing struggle forges the reality for equality of opportunities and conditions between men and women in society and politics. The method employed both in data gathering and narrative structuring was the inductive, and bibliographic research consists in works, articles, legislation, and institutional websites, such as IBGE and TSE, providing necessary substructure for building this article. In conclusion, it is possible to confirm that the partisan institutional violence, sometimes silent, sometimes not, affects women in a way that represents a strong barrier to women's participation in politics.
\end{abstract}

Keywords: Women's empowerment. Women's political participation. Fighting political violence.

${ }^{1}$ O texto que se apresenta é fruto de palestra proferida na solenidade de encerramento da Semana
da Campanha Paz em Casa, campanha essa de iniciativa da Ministra Carmen Lúcia quando então,
presidia, o CNJ, promovido pelo Tribunal de Justiça de Santa Catarina, por intermédio da Coor-
denadoria da Mulher em Situação de Violência Doméstica e Familiar - CEVID, coordenado pela
Desembargadora Salete Silva Somariva. O tema central da Campanha Paz em Casa é a mulher,
vítima de violência. Assunto de extrema importância jurídica e social e que tem relação direta
com o empoderamento feminino muitas vezes alcançado pela participação da mulher na política. Artigo recebido em 23 jul. 2019 e aprovado em 10 ago. 2019. 


\section{Introdução}

A temática do artigo traduz duas importantes vertentes que se conectam pela atualidade, relevância e, em especial, pela necessidade histórica: participação da mulher na política e empoderamento, dando suporte a uma terceira que tem se destacado no Brasil e no mundo que é a violência contra a mulher e, e aqui especificamente, a violência política.

A mulher ainda está sujeita às violências, incluindo a violência institucional partidária e o combate a todas as formas é o que se busca por meio de campanhas, movimentos sociais, intensificação da legislação e, principalmente, pela consciência da própria mulher em ocupar todos os lugares que ela quer.

Nesse contexto, o empoderamento feminino, longe de representar uma expressão da "moda" se apresenta como mecanismo hábil, também, no combate às violências estimulando a participação política da mulher.

O empoderamento, assim, tem como núcleo o fortalecimento emocional, econômico e político que levam à autonomia e encorajamento da mulher proporcionando condições de combater a violência física, verbal, psicológica, patrimonial e moral e todas as formas de violência, incluindo-se a institucional partidária, além do reconhecimento de que o fortalecimento da posição da mulher na sociedade não é somente uma questão legal, mas, também de justiça social.

Eventos e campanhas nacionais têm sido realizados nesse sentido, como o a campanha denominada "16 dias de ativismo pelo fim da violência contra mulheres" 2 , iniciando no dia 25 de novembro, Dia Internacional de Não Violência Contra as Mulheres - com término em 10 de dezembro dia Internacional dos Direitos Humanos. Período em que foram realizadas várias ações, culturais, acadêmicas e institucionais. Além de eventos, instituições têm desenvolvido trabalho e atividades voltadas ao estudo, forma-

\footnotetext{
${ }^{2}$ A campanha teve início em 1991, a partir de uma iniciativa de mulheres de diferentes países, reunidas pelo Centro de Liderança Global de Mulheres (Center for Women's Global Leadership - CWGL/EUA). Fundado pela feminista Charlotte Bunch, em 1989, o centro, atua no desenvolvimento de programas para preparar as mulheres para liderança. Durante esse período ocorre uma outra data importante: o Dia da Mobilização de Homens pelo Fim da Violência contra a Mulher, Campanha Laço Branco, que acontece no dia 06 de dezembro, data que marca o massacre de 14 mulheres, estudantes de engenharia da Escola Politécnica de Montreal - Canadá, ocorrido, em 1989, por um homem que entendia que mulheres não poderiam ter acesso a cursos de engenharia.
} 
ção, e movimentos voltados a dar a mulher conhecimento e condições de enfrentar o universo político, profissional e social, a exemplo do Instituto AEQUALIS de Liderança Feminina, criado em fevereiro de 2019, o qual direciona esforços para proporcionar conhecimento, formação, capacitação e instrumentalização às mulheres para o desenvolvimento da liderança, bem como, promover o fortalecimento, apoio e estimulo à participação na gestão e tomada de decisões nas organizações públicas e privadas, e a difusão de práticas e estratégias que proporcionem a igualdade de gênero ${ }^{3}$.

Há que se fazer, ainda, referência ao Fórum Suprapartidário de Santa Catarina, coordenado pela publicitária Marianne Cristina Tillmann que reúne mulheres de vários partidos políticos para a disseminação de assuntos de interesse político da mulher em seminários, palestras, cursos de capacitação e confraternização.

Portanto, a principal finalidade da temática é trazer como ponto focal o empoderamento da mulher como instrumento de enfrentamento de vários dos obstáculos que impedem seu protagonismo, incluindo o campo político. A hipótese relacionada ao problema, na pesquisa, tem como fundamento a eficácia da proteção legal como elemento garantidor da paridade de direitos entre homens e mulheres, nos partidos políticos, capazes de estimular, manter e eleger as mulheres, posto que a violência contra a mulher nos próprios partidos políticos em que atuam muitas vezes é silenciosa, outras não, além de ser revestida de falso interesse coletivo o que se traduz na falta de apoio financeiro e logístico nas campanhas, impedimento de manifestação verbal nos encontros partidários, ausência de convites para a participação em reuniões, escolha de candidatos homens em substituição de mulheres com perspectiva de eleição, utilização de candidatas "laranja" e outras condutas em que a mulher é colocada em segundo plano.

O artigo está estruturado em quatro partes. A primeira será dedicada a qualificar a categoria "empoderamento" como um mecanismo de fortalecimento da mulher rumo ao alcance de sua autonomia de ação seja na sociedade, na política ou em qualquer lugar em que ela queira estar e se desenvolver. A segunda tratará de uma breve incursão histórica sobre a mulher na sociedade e suas primeiras conquistas políticas, mostrando que a atualidade, não reflete o ideal, mas, não deixa de representar um avanço, mesmo que a passos lentos. A terceira parte retratará as conquistas jurídicas da mulher no campo político o que representa um caminho sem volta e a

${ }^{3}$ Art. $2^{\circ}$ do Estatuto do Instituto AEQUALIS de Liderança Feminina

Resenha Eleitoral (Florianópolis), v. 23, n. 1, p. 51-70, 2019 
continuidade da luta é uma realidade em prol do verdadeiro estado equitativo entre homens e mulheres na sociedade e na política. A quarta e ultima parte tratará do forte vinculo entre o empoderamento político no combate à violência institucional partidária como suporte de posicionamento da mulher e incentivo a sua participação na política.

Empoderamento feminino, a política e combate à violência estão, são temas efetivamente, interconectados, exigindo para sua plena compreensão uma análise interdisciplinar e sistemática traçando uma linha cronológica e temporal sobre a mulher na história da humanidade e suas lutas e conquistas jurídicas, sociais e políticas.

\section{Empoderamento não é somente uma palavra da "moda"}

A Mulher tem protagonizado pautas de discussões e de ações na constante busca da valorização e reconhecimento de sua igualdade de capacidade e condições para ocupar espaços decisórios e de gestão, profissionais e políticos.

Lutas são travadas diariamente pelas mulheres que buscam o reconhecimento social que a legislação já concedeu, afinal, diz a Constituição Federal/88 em seu artigo 5, inciso I que "homens e mulheres são iguais em direitos e obrigações".

Ao lutarem buscarem a igualdade de direitos, condições e oportunidades as mulheres se posicionam e empreendem nos campos: social, político e econômico, participando ativamente de debates públicos, discussões e tomadas de decisões, importantes para o futuro da sociedade. É a partir da conquista de espaços e maior participação que a mulher sai da invisibilidade para empoderar-se socialmente.

Nesse sentido, o empoderamento feminino é expressão que denota certo "modismo" e mesmo em alta, ainda há resistência à compreensão de seu verdadeiro significado que é o fortalecimento de uma parcela da sociedade que vivencia um descompasso entre sua dimensão quantitativa - já que as mulheres representam mais de 50\% da população mundial - e sua expressão de cidadania e participação social em condições de igualdade com os homens (ALVES, 2019).

Empoderar a mulher é dar a ela condições de crescimento pessoal, social e profissional reconhecendo a igualdade intelectual em relação aos homens. 
As inegáveis diferenças biológicas entre homens e mulheres não pressupõem qualquer outra diferença capaz de representar redução da capacidade da mulher em qualquer campo de atuação. Pelo contrário, as diferenças biológicas podem convergir para o sucesso do empreendimento familiar, empresarial, institucional ou qualquer outra relação pessoal ou profissional entre as pessoas.

A relevância do tema provocou a manifestação da ONU Mulher ${ }^{4}$ que, em 2010, criou um documento com 7 princípios básicos de empoderamento feminino no âmbito profissional e social:

1. Estabelecer liderança corporativa sensível à igualdade de gênero, no mais alto nível.

2. Tratar todas as mulheres e homens de forma justa no trabalho, respeitando e apoiando os direitos humanos e a não discriminação.

3. Garantir a saúde, segurança e bem-estar de todas as mulheres e homens que trabalham na empresa.

4. Promover educação, capacitação e desenvolvimento profissional para as mulheres.

5. Apoiar empreendedorismo de mulheres e promover políticas de empoderamento das mulheres através das cadeias de suprimentos e marketing.

6. Promover a igualdade de gênero através de iniciativas voltadas à comunidade e ao ativismo social.

7. Medir, documentar e publicar os progressos da empresa na promoção da igualdade de gênero.

O empoderamento feminino só se estabelece a partir da consciência coletiva, da sororidade, da ajuda mútua, da união das mulheres para o fortalecimento da igualdade de todas, porque a contribuição da mulher é essencial para a melhoria do mundo, tanto no aspecto humano como na política, na economia, na ciência e na sustentabilidade.

Não se trata de um movimento social.

É a ação de dar poder à mulher para que ela reconheça em si e nas outras mulheres valores, capacidade e condições necessárias para sua emancipação e autoconfiança, fatores imprescindíveis para a atuação da mulher na sociedade e na política.

${ }^{4}$ ONU MULHER. Disponível em: www.onumulheres.org.br. Acesso em julho de 2019. 


\section{Breve incursão histórica sobre a mulher na sociedade e na política}

A compreensão do papel da mulher na sociedade e conhecer as precursoras que trilharam o longo caminho da abertura de espaço da mulher na política estimula a reflexão do quanto é importante dar continuidade na busca da verdadeira igualdade de condições.

A própria participação política funciona como fortalecimento da emancipação, autonomia e do exercício da cidadania, além de também representar um mecanismo de combate às violências.

Observa-se que no âmbito jurídico mudanças significativas ocorreram em relação à mulher com o reconhecimento da igualdade em relação aos homens diante da lei, a criação de medidas protetivas, a exemplo da lei Maria da Penha (Lei 11.340/2006) e a Lei do Feminicídio (Lei n. 13.104/2015), todavia, na esfera sociocultural verifica-se testilha constante no alcance do reconhecimento da igualdade (já reconhecida por lei), do respeito e derrocada dos obstáculos e do preconceito.

Do ponto de vista histórico, desde os primórdios da humanidade o desvalor talvez seja a maior barreira a superar pelas mulheres, porque dele derivam outras dificuldades.

$\mathrm{O}$ androcentrismo como elemento de identificação da humanidade remonta à cultura grega, berço de grandes filósofos e onde a mulher - contrariando a valorização civilizatória do saber - era excluída dos espaços de conhecimento. Para os romanos a legitimação da discriminação feminina, ocorreu por intermédio das instituições jurídicas, principalmente o pater familia que atribuía ao homem o poder sobre a mulher, os filhos, os escravos, "perpetuando essa assimetria" (COLLING, 2004, p.14).

Para recuperar a presença feminina na história e na sociedade, foi "necessária a construção de um novo mapa, de uma metáfora, desconfiando das categorias dadas como universais e, ao mesmo tempo privilegiando as singularidades, as pluralidades, as diferenças", afirma Ana Colling (2004, p.14).

A partir de uma visão antropológica, a estrutura social possuía forte cunho comunitário (ENGELS, 2006) e primitivamente homens e mulheres, exceto pela força física e diferenças biológicas, eram iguais no sentido de decidirem no grupo e terem atribuições específicas e complementares no grupo social. Os homens caçavam e as mulheres tomavam conta da 
prole, da alimentação e dos afazeres de manutenção diária do grupo, o que justifica, de certa forma e sem adentrar no caráter científico, a visão retilínea do homem e a visão periférica da mulher. Durante o período paleolítico, homens e mulheres detinham o poder decisório sobre o grupo de uma maneira mais igualitária. Mark Dyble (2015, p. 1-3), antropólogo que desenvolveu estudo nesse sentido, explica que o desenvolvimento da agricultura e consequentemente o acumulo de recursos, as desigualdades começaram a emergir. A poligamia e o aumento da prole propiciaram alianças parentais masculinas que fortaleceram os homens na sociedade.

$\mathrm{O}$ advento da propriedade privada também contribuiu para o desequilíbrio de gênero na humanidade. Tinha por base as conquistas territoriais e, consequente, espaços de poder, os homens passaram a assumir o papel de "administradores" e conquistaram um monopólio político que deflagrou o início das desigualdades sociais (SOARES, 1978).

A certeza da paternidade, até então detida somente pela mulher, afinal a filiação somente podia ser contada por "linha feminina" (ENGELS, 2006), passou a ter relevância na questão da propriedade privada, gerando, o fortalecimento do regime patriarcal, que daí em diante, demarcou um forte poder do homem sobre a mulher e o caráter privatístico da educação feminina com restrições, como confinamento e proibições.

O desfavorecimento em relação ao homem, controlado pelo domínio e violência que por vezes se manifesta fisicamente e em outras de forma simbólica, conforme Pierre Bourdieu (2005), fez com que durante muito tempo a mulher ficasse relegada à funções estritas ao lar, consideradas como atividade de menor importância e, portanto, sem contribuição direta e significativa para o progresso socioeconômico, o que justificava a limitação da participação das mulheres nos processos decisórios.

Da condição de submissão total à de protagonista de sua própria história, a mulher tem, paulatinamente "reconquistando" seu papel na sociedade, diante do que um dia representou em relação à situação de igualdade ao homem, e sua ascensão social por conta, principalmente, das conquistas jurídicas ao longo do tempo.

Embora durante séculos a desigualdade jurídica, social e política entre homens e mulheres, tenha sido enorme é inegável que avanços importantes ocorream, fruto da luta pela liberdade, emancipação e isonomia de direitos. 
Ainda no campo histórico, importante destacar algumas mulheres que marcaram a humanidade por sua posição de comando e poder o que não deixa de ser também uma participação política, a exemplo de Cleópatra que governou o Egito de 51 a. C.-30 a. C., Maria Stuart (Escócia 1542-1567), Catarina de Médici (Florença, na Itália, e França no período de 1547-1559), mas, a conquista do poder de governar passava longe da questão do voto e das lutas pela igualdade de direitos e deveres entre mulheres e homens.

Os primeiros movimentos da mulher na política e na luta pela paridade de direitos datam do período anterior à Revolução Francesa.

Para a manutenção da força pública e para as despesas da administração, as contribuições da mulher e do homem são iguais; ela participa de todos os trabalhos enfadonhos, de todas as tarefas penosas; ela deve, portanto, ter a mesma participação na distribuição dos lugares, dos empregos, dos encargos, das dignidades e da indústria.

Esta é a redação do Artigo XIII da Declaração dos Direitos da Mulher e da Cidadã, proposta por Olympes de Gouges ${ }^{5}$, em 1791, dois anos após o início da Revolução Francesa, em complemento à Declaração dos Direitos do Homem e do Cidadão, promulgada durante a Revolução Francesa.

O que a moveu a redigir este documento foi a própria Revolução Francesa que teve como lema "Liberdade, Igualdade e Fraternidade", inspirando, em parte, no movimento pelo direito à participação política da mulher. E também porque a Declaração dos Direitos do Homem e do Cidadão, não fez qualquer referência à inclusão da mulher, (1748-1793).

O encaminhado do documento à Assembleia Nacional da França para análise e aprovação, a exemplo do que ocorrera com a Declaração dos Direitos do Homem e do Cidadão, em agosto de 1789, acabou por ser interpretado como uma afronta levando sua autora à guilhotina.

\footnotetext{
${ }^{5}$ Marie Gouze, mais conhecida como Olympe de Gouges (1748-1793). Em 1793 ela foi guilhotinada em Paris. E a condenação deveu-se ao fato de ela ter-se oposto aos conhecidos revolucionários Robespierre e Marat, que a consideraram mulher "desnaturada" e "perigosa demais". Ao ser conduzida à morte Olympe de Gouges teria afirmado: "A mulher tem o direito de subir ao cadafalso; ela deve ter igualmente o direito de subir à tribuna". Disponível em: https://periodicos.ufsc.br/index.php/interthesis/article/viewFile/911/10852. Acesso em junho de 2019.
} 
Sua morte, entretanto, não foi em vão, pois, a Declaração da Mulher e da Cidadã, inspirou a Declaração Universal dos Direitos Humanos, aprovada pela ONU em 1948, em muitos de seus artigos sendo o mais conhecido o primeiro artigo dos dois documentos:

Artigo I - Todos os seres humanos nascem livres e iguais em dignidade e direitos. São dotados de razão e consciência e devem agir em relação uns aos outros com espírito de fraternidade.

Artigo II - A mulher nasce livre e permanece igual ao homem em direitos. As distinções sociais só podem ser fundamentadas no interesse comum.

No mesmo período as reinvindicações originadas do proletariado, do qual faziam parte as mulheres, fundadas nas campanhas republicanas e abolicionistas e pela luta de classes, não tardaram a incitar o espírito guerreiro das mulheres a expandir sua luta também para o campo político.

A militância das operárias, a coragem das professoras, a ousadia das intelectuais, fizeram o contraste necessário para a inauguração do importante período histórico para o alcance da emancipação e do empoderamento feminino.

Tal quadro permite a compreensão das diversas reivindicações das mulheres que marcaram o final do Século XVIII e início do XIX e que não tardaram a bater nas portas do Brasil.

Em 1827 foi criada a primeira legislação (Decreto Imperial de 15/10/1827 - Lei Geral) dedicada à educação feminina, com a criação das escolas primárias que admitiam meninas, porém, com uma formação direcionada às prendas domésticas, o que correspondeu à saída da mulher para o mundo do trabalho.

Em reforço à luta pelo voto feminino no Brasil, encontra-se a feminista Berha Maria Julia Lutz, filha de pai suíço-brasileiro, Adolfo Lutz, grande nome da medicina no Brasil, que iniciou campanha sufragista à frente da Liga pela Emancipação Intelectual da Mulher, convertida em 1922, na Federação Brasileira pelo Progresso Feminino (FBPF). Contou com o apoio da impressa nacional e internacional que auxiliou na divulgação da causa, o que deflagrou a criação de grupos de apoio e associações em vários pontos do Brasil. 
O cenário que protagonizou o direito da mulher de votar e ser votada, no Brasil, tem como pano de fundo o período de governo provisório liderado por Getúlio Vargas, que defendia o pensamento populista em contraponto ao federalismo e o enfraquecimento das oligarquias regionais.

A estratégia governamental de Getúlio Vargas previa três metas principais, ou seja, a recuperação econômica, sobretudo, cafeeira, a organização dos direitos e deveres dos trabalhadores ${ }^{6}$, sem qual não alcançaria o seu terceiro objetivo: o avanço da produção industrial.

Produto de intensa, longa e árdua luta pelo reconhecimento dos direitos políticos da mulher, em 24 de fevereiro de 1932, Vargas assina o Decreto 21.076, também conhecido como Código Eleitoral Provisório, assegurando às mulheres, de modo facultativo, o direito de votar e ser votada inaugurando um de seus mais importantes marcos legislativos.

Um pouco depois, em 1946, nova alteração na legislação estendeu a obrigatoriedade do voto às mulheres, porquanto, o Decreto de 1932, previa tal possibilidade somente aos homens.

A primeira iniciativa para pedido de voto foi a da odontóloga Izabel de Matos Dilon que evocou a Lei Saraiva em razão do título profissional e científico (1880), mas, foi negado.

O primeiro voto feminino no Brasil, entretanto, aconteceu cinco anos antes da lei criada por Getúlio Vargas, em 1928 no Rio Grande do Norte. O primeiro caso foi na cidade de Mossoró quando Celina Guimarães Viana, com 29 anos à época, cadastrou-se em um cartório para ser incluída na lista dos eleitores do pleito que ocorreria no mesmo ano.

No mesmo Estado na cidade de Lajes, Alzira Soriano de Souza, pleiteou o cargo de prefeita com êxito nas eleições, no entanto, em ambas as situações a comissão de poderes do senado impediu a concretização dos atos.

\footnotetext{
${ }^{6}$ Em 26 de novembro de 1930, Vargas criou o Ministério do Trabalho Indústria e Comércio. Em março do ano seguinte foi promulgada a primeira lei sindical brasileira (Decreto $\mathrm{n}^{\circ}$ 19.770), que tinha como uma das finalidades as organizações sindicais tanto de trabalhadores como dos empregadores (empresários) constituindo em instituições colaborativas do Estado. Tal regulamentação disciplinava, reconhecia e controlava as reivindicações por parte dos trabalhadores. Mais tarde, em $1^{\circ}$ de maio de 1940, foi criado o salário mínimo nacional e em 1943, é criada a Consolidação das Leis do Trabalho (CLT), que sistematizou em um único documento as leis e normas pertinentes às relações de trabalho, voltando-se fundamentalmente para direitos do trabalhador, a organização sindical e a Justiça do Trabalho.
} 
Carlota Pereira de Queirós, médica, pedagoga e escritora, cunhou seu nome na história da política feminina no Brasil, tornando-se, em 1933 a primeira mulher deputada federal, participando ativamente da Assembleia Nacional constituinte entre 1934 e 1935 e suas principais bandeiras era o direito das mulheres e das crianças. Outras conquistas femininas históricas:

a) A professora Antonieta de Barros foi eleita para a Assembleia de Santa Catarina (1934), passando a ser a primeira parlamentar negra da História do Brasil.

b) A Princesa Isabel, foi a primeira Senadora do período Imperial de acordo com o que estabelecia o artigo 46 da Constituição de 1924: "Os príncipes da Casa Imperial são Senadores por direito e terão acento no Senado logo que chegarem à idade de 25 anos". Na época, grande discussão foi travada no Senado em razão da interpretação do dispositivo constitucional com opiniões contra e a favor.

c) Eunice Mafalda Berger Michiles tornou-se a primeira senadora do Brasil, no Período Republicano, na condição de suplente (1979);

d) Esther de Figueiredo Ferraz ocupa, como primeira mulher, o cargo de Ministra da Educação e Cultura (24 de agosto de 1982 a 15 de março de 1985);

e) Roseana Sarney tornou-se a primeira governadora brasileira (1995);

f) Dilma Rousseff (2010) ocupou o mais alto cargo eletivo no Brasil, a Presidência da República, sendo reeleita em 2014.

A história revela que gradativamente as mulheres vêm ocupando espaços que antes eram de exclusividade dos homens, promovendo uma política com contornos mais igualitários, o que não significa que tenha sido fácil.

\section{O protagonismo da mulher na política: um caminho sem volta}

Em número, as mulheres perfazem a maioria no Brasil e segundo os dados do Instituto Brasileiro de Geografia e Estatística (IBGE), divulgados em 2013, a população estimada no Brasil, é de 201.032.714 habitantes sendo 103,5 milhões de mulheres, o que equivale a 51,4\% da população (razão de 96 homens para cada 100 mulheres. 
A proporção também reflete o eleitorado ${ }^{7}$ revelando que grande parcela da população votante é formada por mulheres ${ }^{8}$.

Estamos vivenciando um momento de amadurecimento da democracia o que também significa a transição de uma democracia meramente representativa para uma democracia efetivamente participativa: campo fértil para a atuação feminina na política.

Em um Estado Democrático de Direito a politização da mulher é condição natural que se desenvolve não pela obrigatoriedade legal, mas, pela consciência da importância de sua ativa participação.

O envolvimento da mulher na política, além de representar uma das formas de combate às desigualdades de gênero e de violência, tem como finalidade o enfrentamento do grande desafio de fortalecer e ampliar a participação feminina nos espaços de poder e decisão.

O sistema de cotas (art. 10, $\ 3^{\circ}$, da Lei n. 9.504/97, alterado pela Lei n. 12.034/09), assegura a reserva de 30\% e 70\%, para cada gênero, o que representa na prática um percentual obrigatório de participação feminina nos partidos políticos e consequentemente nas eleições, visa buscar um equilíbrio maior de participação, entretanto, sua eficácia é controvertida e até certo ponto discriminatória porque a efetiva participação deve ser incentivada desde o nascimento, na família, na escola e no grupo social em que se insere a menina.

Além disso, é questionável o valor numérico de 30\% (trinta por cento), pois, ausente qualquer dado que comprove que o percentual estabelecido tenha como fundamento a ciência ou uma metodologia. A verdadeira equidade estipula 50\% (cinquenta por cento), não somente em relação às candidaturas, mas, também em vagas nas executivas dos partidos, nas cadeiras do parlamento e nas estruturas de cargos no Poder Legislativo, Executivo e Judiciário.

\footnotetext{
${ }^{7}$ Brasil tem 147,3 milhões de eleitores aptos a votar nas Eleições 2018. Disponível em: http:/ /www.tse.jus.br/imprensa/noticias-tse/2018/Agosto/brasil-tem-147-3-milhoes-de-eleitores-aptos-a-votar-nas-eleicoes-2018. Acesso em 21 de novembro de 2018.

${ }^{8}$ Segundo dados do Cadastro Eleitoral, a maior parte do eleitorado brasileiro pertence ao gênero feminino. Ao todo, são 77.337.918 eleitoras, o que representa 52,5\% do total. Já o gênero masculino reúne 69.901 .035 cidadãos, representando 47,5\% do eleitorado. Disponível em: http://www.tse.jus.br/imprensa/noticias-tse/2018/Agosto/brasil-tem-147-3-milhoes-de-eleitores-aptos-a-votar-nas-eleicoes-2018. Acesso em 21 de novembro de 2018.
} 
Portanto, o que se exige é a igualdade de gênero e condições em todos os níveis de participação na sociedade, desde o mercado de trabalho até os cargos eletivos.

A sociedade sempre destinou à mulher um papel restrito no contexto político partidário e falar em participação feminina no universo da política partidária é preciso, discorrer também sobre a consciência política da mulher como condição preliminar no sentido de compreender o seu papel como cidadã, isso porque de nada adianta ter direito de votar e ser votada se não há estímulo à sua efetiva participação.

Com total exclusão em um cenário histórico até a década de 1930 - quando o Decreto 21.076, conhecido como Código Eleitoral Provisório, assegurou às mulheres, de modo facultativo, o direito de votar e ser votada, configurando a gênese da participação política feminina partidária no Brasil - a mulher, hoje, tem se aproximado da política, ainda que de forma tímida.

A política foi, e ainda é marcada pelo domínio masculino, portanto, todo e qualquer avanço no que se refere a integrar a mulher na política e nos espaços decisórios, tem um significado que vai além do contexto histórico devendo ser encarado como importante passo rumo à igualdade de gênero, do empoderamento e emancipação feminina.

Somente a título de informativo, o concurso para a magistratura em Santa Catarina, edição de 2018, teve aprovação de mulheres em número superior aos homens o que demonstra que quando há disputa em igualdade de condições o número de mulheres e homens se equiparam.

Não se pode negar o crescimento e a evolução das condições da participação feminina na política, porém, as desigualdades estruturais ainda são reais e as medidas jurídicas e sociais que podem acelerar esse processo estão longe do ideal.

Nas eleições de 2018, mesmo com toda a campanha do Tribunal Superior Eleitoral e dos Tribunais Regionais Eleitorais, além de outas instituições, mesmo havendo um aumento de eleitas, não foi significativo o suficiente de forma a revelar grande avanço.

Naturalmente a própria edição da lei foi fruto de reivindicações femininas por mais espaço na esfera pública eleitoral e é possível notar o aumento das candidaturas femininas.

Dados do Tribunal Superior Eleitoral mostram que no Senado dos 54 (cinquenta e quatro) ocupantes nas eleições de 2010 a 2018, somen- 
te 7 (sete) mulheres foram eleitas. A comparação no Senado foi realizada a partir do ano de 2010, considerando que nesse ano, também foram eleitos 54 senadores em contrapartida com 2014 que foram 27 (vinte e sete). $\mathrm{Na}$ Câmara dos Deputados, no período de 2014 a 2018, foram eleitas 51 (cinquenta e uma) mulheres e em 2018, 77 (setenta e sete). Nas Assembleias Legislativas, em 2014 foram eleitas 119 (cento e dezenove) mulheres e em 2018, 161 (cento e sessenta e uma) mulheres.

A cota partidária ao mesmo tempo em que representa uma forma de discriminação tem determinada importância em num dado momento histórico, e não há dúvida que está fadado à extinção ante ao aumento da participação efetiva da mulher na política pela conscientização de seu papel no universo partidário, porque o sentido da lei não é somente uma representação nominal na lista de candidatos.

No Brasil, o número de mulheres eleitas nos mais diversos cargos políticos ainda está aquém do que se espera e fica aqui uma mensagem de incentivo para as próximas eleições para que as mulheres realmente se conscientizem de que o lugar de mulher também é na política e esse é um caminho sem volta.

\section{Algumas considerações sobre o empoderamento feminino como forma de combate à violência política contra a mulher}

A ideia da interconexão entre o empoderamento político e a questão do combate às violências contra a mulher, em especial a violência política, não tem a finalidade, neste espaço, de trazer estatísticas ou discursar sobre a segurança pública, mas, de traçar algumas considerações sobre como a inserção da mulher na política pode resultar no fortalecimento de seu posicionamento verbal e postural refletindo também no encorajamento e atitudes proativas quando estiverem diante de situações que possam representar algum tipo de violência.

A violência física é a mais conhecida das atitudes aviltantes, entretanto, outros tipos de violências coloca a mulher em situação de vulnerabilidade, como a violência emocional, sexual, verbal, incluindo nesse rol a violência institucional que também abrange a postura masculina nos partidos políticos.

Os movimentos feministas contemporâneos têm trabalhado para mudar essa realidade e intervém positivamente no esforço de sustentar e 
promover mudanças de pensamento e de ações para uma maior conscientização cultural sobre a violência, iniciando pela situação da mulher em casa (violência doméstica) expandindo para todos os demais tipos (HOOKS, 2018).

Embora histórica a violência contra as mulheres não é possível considerá-la natural, normal ou comum. Não há nada que justifique a naturalidade da violência.

É preciso desnaturalizá-la e grande parte da mudança de rumo nessa parte nefasta da história da mulher na humanidade de deve aos movimentos feministas de ontem e de hoje, que sempre lutaram pela liberdade da mulher, tanto em relação à expressão como a conquista de espaços de poder e decisórios, o que representam precedentes importantes na compreensão do tema, sobretudo, na seara específica da violência contra a mulher na política.

As contribuições dos movimentos em prol da igualdade de oportunidades entre mulheres e homens, extensivas à equidade de gênero, foram decisivas no processo de democratização do país. Nesse sentido, destaca-se a luta pelo direito de votar e ser votada, a luta contra a violência doméstica e sexual, contra a desigualdade relativa ao acesso ao poder e ao mercado de trabalho (CARNEIRO, 2003).

O posicionamento literário sobre a violência política contra as mulheres, abrangendo a América Latina, trata da questão não somente da violência física, mas, estende para outros tipos de violência, como a moral, sexual, psicológica, simbólica e econômica (KROOK; SANIN, 2016, p. 125-157).

As agressões se concretizam em forma de ameaças, assédio, críticas ao comportamento, até mesmo à forma de se vestir das mulheres. Estendem-se para as restrições de voz, de sua atuação dentro e fora do partido, além, da velha prática em relação aos recursos econômicos para as campanhas políticas cujos menores valores são destinados à mulher ou até valor nenhum.

A violência contra a mulher, atualmente é tema que tem sido debatido, integra as agendas governamentais, é foco de ações também do terceiro setor, como organizações não governamentais, associações de classe e outros tipos de instituições. 
Os índices que são apresentados pela mídia são assustadores, porém, pouco se fala sobre a violência política, a não ser em período eleitoral em que campanhas são intensificadas para uma maior participação feminina nas eleições.

Talvez o cenário que se apresenta seja fruto não somente de um aumento da violência propriamente dita, mas, pelo redimensionamento da estatística em razão do enfrentamento da mulher, do estímulo às denúncias, pela negativa de aceitar a continuidade de uma postura machista e violenta nos partidos políticos, ou seja, é a voz da mulher ecoando em prol de sua própria libertação, emancipação e autonomia de atitudes.

As campanhas e ações voltadas a capacitar, qualificar e preparar as mulheres para a atuação na política também tem forte reflexo no seu encorajamento para superar as barreiras encontradas na sociedade e nos partidos políticos.

A percepção é a de que a violência contra a mulher, principalmente a institucional partidária é, em realidade, uma reação à ascensão e maior participação feminina na política. Há, em parte, um certo inconformismo masculino em relação às mulheres que têm se preparado e se destacado no mundo político, saindo de sua "zona de conforto" para o exercício efetivo de seus direitos como cidadãs.

A violência institucional partidária, por vezes silenciosa, outras não, atinge as mulheres, representando forte barreira à participação da mulher na política e muito ainda há por fazer para mudar essa realidade.

As mulheres não precisam se masculinizar para serem reconhecidas em igualdade de condições ao homem na política e o velho jargão de que "mulher não vota em mulher" também está a cair por terra, porque, as mulheres votam em outras mulheres que realmente as represente, portanto, o rumo certo a seguir é o da preparação para a participação na política, seja como candidatas ou como apoiadoras, coordenadoras de campanha ou qualquer outra forma de atuação.

Se o lugar da mulher é onde ela quiser, a violência na política como forma de obstaculizar a sua atuação deve ser fortemente combatida.

É para isso e por isso que a sororidade e a união das mulheres são essenciais nessa luta constante que tem no empoderamento feminino um suporte hábil no combate à violência política ou qualquer outro tipo de violência contra as mulheres. 


\section{Considerações finais}

O domínio masculino no mundo político partidário está em declínio frente ao posicionamento das mulheres na sociedade e sua maior participação na política.

O equilíbrio, a paridade, a igualdade de oportunidades entre homens e mulheres é o que se busca.

Apesar de todos os esforços e avanços jurídicos e sociais, bem como de medidas proativas adotadas para uma representação mais equitativa e equilibrada na política e nas posições públicas decisórias, a discriminação e a violência contra as mulheres ainda persistem.

Ações impeditivas ou condicionantes da efetiva participação da mulher na política tomam as mais diversas formas e interferem da evolução da democracia.

As leis protetivas e que asseguram direitos das mulheres em muito auxiliam no enfrentamento das dificuldades que encontram as mulheres que escolhem o caminho da participação política.

Por outro lado, mecanismos de contenção desses avanços trabalham em prol da manutenção das desigualdades e um dos mais vis é a violência política contra a mulher. Nesse sentido, a violência toma todas as formas. Algumas silenciosas como a falta de comunicação e convite para reuniões e encontros partidários, a restrição de voz e a redução de recursos econômicos para a campanha eleitoral. Outras mais explícitas como as agressões verbais, morais, sexuais, ameaças, críticas ao comportamento das mulheres, assédio e chegando, em alguns casos, até à violência física.

Essa violência política somente será reduzida a partir da atitude da mulher em se posicionar nos partidos políticos, na sociedade e no ambiente familiar.

A partir da consciência e ações coletivas, da sororidade, da união das mulheres é que o empoderamento feminino acaba por refletir diretamente no fortalecimento para o enfrentamento da violência política e de outras barreiras convencionais.

A contribuição da mulher e o reconhecimento da igualdade de oportunidades e condições com os homens são essenciais para o desenvolvimento da humanidade a partir de uma visão sistêmica que abrange a ciência, a economia, a política, a sustentabilidade e a sociedade. 
A luta travada no campo político tem como fundamento o direito das mulheres em participar de forma equilibrada e isonômica com os homens; por um engajamento não por causa da cota legal, mas, sim em razão da sua vontade, de sua vocação e exercício de sua cidadania.

A política é uma palavra polissêmica e feminina e nos revela que mulher tem o direito de fazer e estar onde quiser e desejar e de prospectar sem receio a trilha escolhida para enfrentar.

A ampliação dos direitos da mulher, em todos os níveis e aspectos, passa diretamente pela sua atuação na política e participação na elaboração das leis.

Como eleitoras, a voz que brada é a da reinvindicação, como representantes políticas e ocupantes de cargos públicos é a atitude, a maior aliada na concretização e efetividade de igualdade de direitos, deveres e oportunidades.

\section{Referências}

ALVES, Elizete Lanzoni. Empoderamento feminino: rumo certo para a emancipação e autoconfiança. Na Pauta Online. 30 de Março de 2019. Disponível em: http://napautaonline.com.br/2019/03/30/empoderamento-feminino-rumo-certo-para-a-emancipacao-e-autoconfianca/. Acesso em julho de 2019.

AQUINO, Rubim Santos Leão de; FRANCO, Denise de Azevedo; LOPES, Oscar Guilherme P. Campos. História das sociedades - Das comunidades Primitivas Às Sociedades Medievais. Rio de Janeiro: Ao livro Técnico, 1980. BOURDIEU. Pierre. A dominação masculina. 4. ed. Rio de Janeiro: Bertrand Brasil, 2005.

CARNEIRO, Sueli. Mulheres em movimento. Estudos Avançados. V. 17, N. 49. São Paulo: Universidade de São Paulo, 2013.

COLLING, Ana. A Construção Histórica do Feminino e do Masculino.

Gênero e Cultura: questões contemporâneas. STREY Marlene Neves, et al (Org.). Coleção Gênero e Contemporaneidade. Porto Alegre: EDIPUCRS, 2004, p. 14. 
DYBLE. Mark. Sex Equality can explain the unique social structure of hunther-gatherer bands. Science - Research/Report. MSno: REaaa5139/CF/ ANTHRO, 2015. p. 1-3.

ENGELS, Friedrich. A origem da família, da propriedade privada e do Estado. Tradução de Ruth M. Klaus: 3 $3^{\text {a }}$ Centauro Editora, São Paulo, 2006.

HOOKS, Bell. O feminismo é para todo mundo: políticas arrebatadoras. Rio de Janeiro: Editora Rosa dos Ventos, 2018.

KROOK, Mona Lena. SANIN, Juliana Restrepo. Gender and political violence in Latin America. Política y gobierno, vol. 23, n. 1, 2016, p. 125-157.

ONU MULHER. Disponível em: www.onumulheres.org.br. Acesso em junho de 2019.

SOARES, Orlando. A evolução do status jurídico social da mulher. Rio de Janeiro: Rio, 1978.

Elizete Lanzoni Alves - Doutora em Direito Ambiental pela UFSC. Pós-Doutora pela Universidade de Alicante/Espanha. Pedagoga pela UDESC. Presidente da Comissão Permanente de Processo Disciplinar do Tribunal do TJSC. Presidente do Instituto AEQUALIS de Liderança Feminina. Membro e Diretora Acadêmica da Academia Catarinense de Letras Jurídicas - ACALEJ. Membro do Instituto dos Advogados de Santa Catarina. Professora na Academia Judicial do TJSC. 
